\title{
A 13-year experience with gastric neuroendocrine tumors: A single institute study
}

Ji-Yeon Mun, Hyung-Min Chin, Kyong-Hwa Jun

Department of Surgery, St. Vincent's Hospital, College of Medicine, The Catholic University of Korea, Suwon, Korea

Purpose: Gastric neuroendocrine tumors (GNETs) are relatively uncommon. Although they frequently follow indolent clinical courses, GNETs have the potential for metastasis. The aim of this study was to analyze the clinicopathological characteristics of GNETs and explore the prognostic factors associated with overall survival of patients with GNETs.

Methods: All patients who underwent resection of GNETs from 2003 to 2016 at St. Vincent's Hospital were identified retrospectively. Demographic data, tumor characteristics, and survival results were evaluated.

Results: Of the 32 patients with GNETs, 10 patients (31.3\%) had an endoscopic resection and 22 (68.7\%) had a surgical resection. In terms of the European Neuroendocrine Tumor Society (ENETS) tumor-node-metastasis (TNM) staging systems, three (9.4\%), seven (21.9\%), five (15.6\%), $13(40.6 \%)$, and four patients (12.5\%) were classified as stages $0, \mathrm{I}, \mathrm{II}, \mathrm{III}$, and IV, respectively. Overall survival differed significantly according to disease stage. Patients with positive symptoms, larger tumor size, and advanced stage had lower survival rates than those with other types.

Conclusion: ENETS TNM stage is a reliable parameter for assessment of the prognosis of patients with GNETs. Clinical symptoms, tumor size, and TNM stage are associated with survival of patients with GNETs.

Keywords: Neuroendocrine tumors, Stomach, Stage, Survival

\section{INTRODUCTION}

Gastric neuroendocrine tumors (GNETs) are a group of heterogeneous neoplasms traditionally referred to as carcinoid tumors. These tumors are derived from enterochromaffin-like cells that are dispersed throughout the gastrointestinal tract. Epidemiological studies have reported a marked increase in the incidence of these tumors because of the widespread use of endoscopy and an increased awareness of GNETs among clinicians and pathologists [1].

The clinical course of GNETs ranges from indolent to aggressive, and management of these tumors is challenging. Moreover, their

Received: Oct 10, 2017 Accepted: May 3, 2018

Correspondence to: Kyong-Hwa Jun

Department of Surgery, St. Vincent's Hospital, College of Medicine, The

Catholic University of Korea, 93 Jungbu-daero, Paldal-gu, Suwon 16247, Korea

Tel: +82-31-249-7170, Fax: +82-31-247-5347

E-mail: dkkwkh@catholic.ac.kr

Copyright @ C Korean Society of Surgical Oncology

This is an Open Access article distributed under the terms of the Creative Commons Attribution Non-Commercial License (http://creativecommons.org/licenses/by-nc/4.0) which permits unrestricted non-commercial use, distribution, and reproduction in any medium, provided the original work is properly cited. stratification into prognostic groups has been hampered by the lack of a unified staging system. In 2000, the World Health Organization (WHO) established the first classification system, which in 2010 was updated and redefined into four categories. Several studies confirmed the prognostic significance of this system for survival of neuroendocrine tumor (NET) patients [2-4]. The European Neuroendocrine Tumor Society (ENETS) proposed a tumornode-metastasis (TNM) staging system in 2006 [5,6], the prognostic significance of which has been validated [2-4].

Although they frequently exhibit relatively indolent clinical courses, GNETs have the potential for lethal progression, especially in patients who present with advanced disease. Therefore, timely therapeutic intervention is important for GNET patients. Currently, early detection and surgical resection is the only reliable treatment for GNETs. Few studies have reported the prognosis of GNET patients after surgery and the prognostic significance of ENETS TNM staging system in patients with gastric cancer. In this study, we analyzed the clinicopathologic characteristics of GNETs and identified prognostic factors for overall survival in patients with GNETs. 


\section{METHODS}

\section{Patients}

With the approval of the Institutional Review Board, we retrospectively reviewed 32 consecutive cases of GNETs registered between January 2003 and December 2016 at St. Vincent's Hospital. Only patients with resected GNETs were included. Patients who underwent tumor biopsy with residual local disease and no formal endoscopic or surgical resection were excluded. Demographics, clinical manifestations, comorbidities, tumor characteristics, and treatment data were collected by review of the medical records.

All of the patients underwent endoscopic or surgical resection. Surgical resections were performed by experienced surgeons following the Japanese Gastric Cancer Association (JGCA) guidelines. As there is no standard adjuvant therapy for GNET patients, chemotherapy was advised if the patients had lymph node metastasis or serosa invasion. The chemotherapy regimen was epirubicin plus cisplatin referring to the regimen of small cell lung cancer, or fluorouracil-based chemotherapy referring to the regimen of

Table 1. ENETS TNM staging system for gastric neuroendocrine tumors

\begin{tabular}{|c|c|}
\hline Stage & Definition \\
\hline \multicolumn{2}{|c|}{ T-primary tumor } \\
\hline $\mathrm{TX}$ & Primary tumor cannot be assessed \\
\hline T0 & No evidence of primary tumor \\
\hline Tis & In situ tumor/dysplasia (<0.5 mm) \\
\hline $\mathrm{T} 1$ & $\begin{array}{l}\text { Tumor invades lamina propria or submucosa and } \\
\leq 1 \mathrm{~cm}\end{array}$ \\
\hline T2 & $\begin{array}{l}\text { Tumor invades muscularis propria or subserosa or } \\
>1 \mathrm{~cm}\end{array}$ \\
\hline T3 & Tumor penetrates serosa \\
\hline T4 & $\begin{array}{l}\text { Tumor invades adjacent structures for any } T_{\text {, add }} \\
\text { (m) for multiple tumors }\end{array}$ \\
\hline \multicolumn{2}{|c|}{ N-regional lymph nodes } \\
\hline NX & Regional lymph nodes cannot be assessed \\
\hline No & No regional lymph node metastasis \\
\hline N1 & Regional lymph node metastasis \\
\hline \multicolumn{2}{|c|}{ M-distant metastasis } \\
\hline MX & Distant metastasis cannot be assessed \\
\hline Mo & No distant metastases \\
\hline M1 & Distant metastasis \\
\hline \multicolumn{2}{|c|}{ Stage (T/N/M) } \\
\hline 0 & Tis/No/MO \\
\hline I & T1/No/MO \\
\hline Ila & T2/NO/MO \\
\hline$\| b$ & T3/No/MO \\
\hline IIla & T4/NO/MO \\
\hline$\| l l b$ & Any T/N1/M0 \\
\hline IV & Any T/Any N/M1 \\
\hline
\end{tabular}

ENETS, European Neuroendocrine Tumor Society; TNM, tumor-node-metastasis. gastric cancer.

All tissues were reviewed by a pathologist and classified according to the $2010 \mathrm{WHO}$ grading classifications. We evaluated the basic clinical features and survival data between WHO grades and ENETS TNM staging system (Table 1).

\section{Statistical methods}

Statistical analyses were performed using SPSS software version 21.0 (IBM Corp., Armonk, NY, USA). Survival was calculated from the time of resection to the date of the most recent clinical follow-up or the date of death. Survival data were analyzed using the Kaplan-Meier method with the log-rank test. A value of $\mathrm{P}<0.05$ was considered indicative of statistical significance.

\section{RESULTS}

\section{Clinicopathological outcomes}

A total of 32 consecutive GNETs patients were identified in this study, and their clinicopathologic features are summarized in Table 2. Of the 32 patients, $22(68.7 \%)$ were males and $10(31.3 \%)$ were females, and the average age at resection was $62.4 \pm 7.5$ years. No patient had a family history of GNETs. Comorbidity rate was $34.4 \%(\mathrm{n}=11)$. Thirteen patients $(40.6 \%)$ had symptomatic presentations secondary to the presence of the tumor; however, no patient had a functional neoplasm.

All patients in this study underwent resection: 10 patients (31.3\%) had an endoscopic resection and 22 (68.7\%) had a surgical resection. Twenty-nine patients (90.6\%) underwent curative resection and three (9.4\%) had gross residual disease after resection secondary to the presence of metastatic disease in the liver and peritoneum.

On pathologic analysis, the average tumor size was $3.9 \pm 9.7 \mathrm{~cm}$, and five patients (15.6\%) had multifocal tumors. Regional lymph node metastases and serosa invasion were found in 15 (46.8) and 13 (40.6\%), respectively. In terms of the ENETS TNM staging systems, three (9.4\%), seven (21.9\%), five (15.6\%), 13 (40.6\%), and four patients (12.5\%) were classified as stages 0 , I, II, III, and IV, respectively. Overall, 10 (31.2\%), three (9.4\%), and 19 patients (59.4\%) had G1, G2, and G3 tumors, respectively. A total of 14 patients $(43.7 \%)$ received adjuvant therapy after the operations.

\section{Clinicopathological characteristics and overall survival of patients with surgical resection}

The median follow-up duration for surviving patients was 91.6 months (range, 15-206 months). The 5-year survival rates based on the ENETS TNM classification were as follows: stage I, 99\%; stage II, 72\%; stage III, 42\%; and stage IV, 34\% (Fig. 1). Overall sur- 
Table 2. Baseline clinical characteristics of all patients

\begin{tabular}{|c|c|}
\hline Variable & Value \\
\hline $\begin{array}{l}\text { Sex } \\
\text { Male } \\
\text { Female }\end{array}$ & $\begin{array}{l}22(68.7) \\
10(31.3)\end{array}$ \\
\hline Age $(y r)$ & $62.4 \pm 7.5$ \\
\hline $\begin{array}{l}\text { Comorbidity } \\
\text { No } \\
\text { Yes }\end{array}$ & $\begin{array}{l}21(65.6) \\
11(34.4)\end{array}$ \\
\hline $\begin{array}{l}\text { Symptoms } \\
\text { No } \\
\text { Yes }\end{array}$ & $\begin{array}{l}19(59.4) \\
13(40.6)\end{array}$ \\
\hline $\begin{array}{l}\text { Tumor location } \\
\text { Upper } 1 / 3 \\
\text { Middle } 1 / 3 \\
\text { Lower } 1 / 3\end{array}$ & $\begin{array}{c}3(9.4) \\
6(18.7) \\
23(71.9)\end{array}$ \\
\hline $\begin{array}{l}\text { Extent of resection } \\
\text { EMR } \\
\text { STG } \\
\text { TG }\end{array}$ & $\begin{array}{r}10(31.3) \\
13(40.6) \\
9(28.1)\end{array}$ \\
\hline $\begin{array}{l}\text { No. of tumors } \\
1 \\
\geq 2\end{array}$ & $\begin{array}{r}27(84.4) \\
5(15.6)\end{array}$ \\
\hline Tumor size $(\mathrm{cm})$ & $3.9 \pm 9.7$ \\
\hline $\begin{array}{l}\text { Depth of invasion } \\
\text { In situ tumor/dysplasia }(<0.5 \mathrm{~cm}) \\
\text { Mucosa/submucosa }(\leq 1 \mathrm{~cm}) \\
\text { Muscularis propria/subserosa/ } \geq 1 \mathrm{~cm} \\
\text { Serosa } \\
\text { Adjacent structures }\end{array}$ & $\begin{array}{r}3 \\
7 \\
9 \\
10 \\
3\end{array}$ \\
\hline $\begin{array}{l}\text { Lymph node metastasis } \\
\text { N0 } \\
\text { N1 }\end{array}$ & $\begin{array}{l}17(53.2) \\
15(46.8)\end{array}$ \\
\hline $\begin{array}{l}\text { Distant metastasis } \\
\text { M0 } \\
\text { M1 }\end{array}$ & $\begin{array}{r}28(87.5) \\
4(12.5)\end{array}$ \\
\hline $\begin{array}{l}\text { Lymphatic invasion } \\
\text { Yes } \\
\text { No }\end{array}$ & $\begin{array}{l}18(56.2) \\
14(43.8)\end{array}$ \\
\hline $\begin{array}{l}\text { Histologic grade } \\
\text { G1 } \\
\text { G2 } \\
\text { G3 }\end{array}$ & $\begin{array}{c}10(31.2) \\
3(9.4) \\
19(59.4)\end{array}$ \\
\hline $\begin{array}{l}\text { ENETS TNM stage } \\
0 \\
\text { I } \\
\text { II } \\
\text { III } \\
\text { IV }\end{array}$ & $\begin{array}{r}3(9.4) \\
7(21.9) \\
5(15.6) \\
13(40.6) \\
4(12.5)\end{array}$ \\
\hline $\begin{array}{l}\text { Adjuvant therapy } \\
\text { No } \\
\text { Yes }\end{array}$ & $\begin{array}{l}18(56.3) \\
14(43.7)\end{array}$ \\
\hline $\begin{array}{l}\text { Recurrence } \\
\text { No } \\
\text { Yes }\end{array}$ & $\begin{array}{r}25(78.1) \\
7(21.9)\end{array}$ \\
\hline
\end{tabular}

Values are presented number (\%) or mean \pm standard deviation. EMR, endoscopic mucosal resection; STG, subtotal gastrectomy; TG, total gastrectomy; ENETS, European Neuroendocrine Tumor Society; TNM, tumor-node -metastasis.

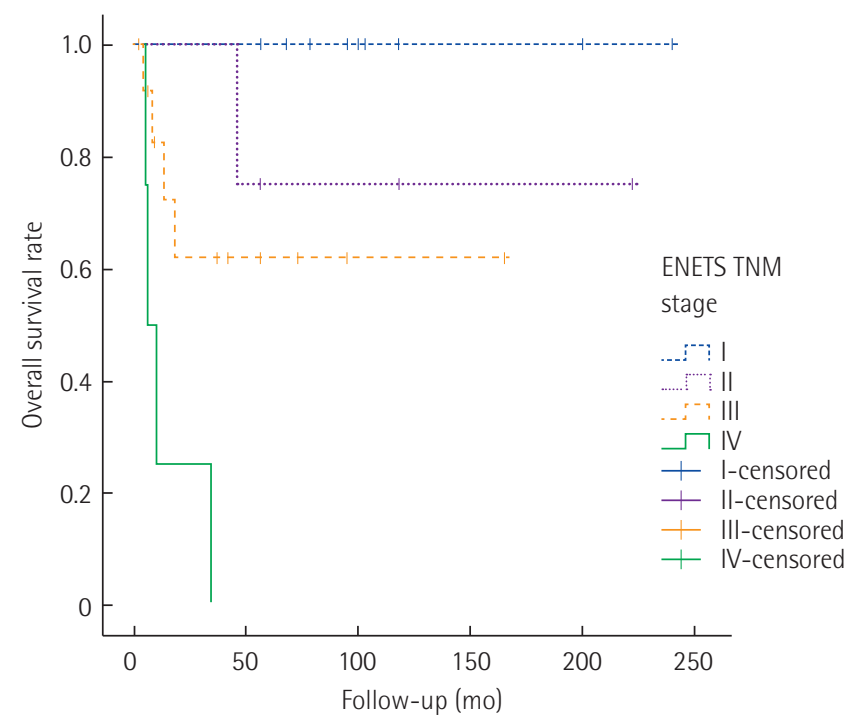

Fig. 1. Survival curve of gastric neuroendocrine tumors patients according to European Neuroendocrine Tumor Society (ENETS) tumor-node-metastasis (TNM) stage.

vival differed significantly according to disease stage.

An analysis was performed on the clinicopathological characteristics to identify the prognostic factors associated with survival in patients with surgical resection. Univariate analysis confirmed that positive symptoms, larger tumor size, and advanced stage exhibited lower survival rates than those with other types. The statistical results for survival time and other data are provided in Table 3. The survival curves are shown in Fig. 2.

\section{DISCUSSION}

The incidence of GNETs has increased over the past few decades due to early detection by endoscopic examination. GNETs show indolent to aggressive biological and clinical behavior. The management of GNETs depends on the type and size of tumor, and on the presence of risk factors such as serosal exposure, tumor proliferation, and metastasis. The prognosis of patients with GNETs is not well-defined because no structured therapeutic approach has been developed.

The classic syndromes associated with functioning NETs include carcinoid syndrome, which is the result of interactions among tumor factors, such as 5-hydroxytryptamine, kinins, and kallikrein, leading to flush, diarrhea, and so forth. Most GNETs are non-functional and present late with mass effects. Kuiper et al. [7] reported that the most common symptoms of non-functional NETs are abdominal pain, weight loss, anorexia, jaundice, nausea, vomiting, and intra-abdominal hemorrhage. GNETs do not have specific symptoms. Tang et al. [8] evaluated 146 gastroenteropancreatic 
Table 3. Clinicopathological characteristics and overall survival of patients with surgical resection

\begin{tabular}{|c|c|c|c|c|c|}
\hline Variable & No. of patients & Median (mo) & IQR & $\chi^{2}$ & P-value $e^{\text {a) }}$ \\
\hline Sex & & & & 0.267 & 0.605 \\
\hline Male & 16 & 26.0 & $6.5-71.5$ & & \\
\hline Female & 6 & 49.0 & $10.5-147.0$ & & \\
\hline Age (yr) & & & & 0.509 & 0.476 \\
\hline$\geq 60$ & 7 & 37.0 & $10.0-67.0$ & & \\
\hline$<60$ & 15 & 40.0 & $7.5-135.0$ & & \\
\hline Comorbidity & & & & 0.098 & 0.754 \\
\hline Yes & 10 & 26.0 & $8.5-65.0$ & & \\
\hline No & 12 & 51.0 & $6.0-140.0$ & & \\
\hline Symptoms & & & & 5.143 & 0.023 \\
\hline Yes & 12 & 15.5 & $6.5-107.5$ & & \\
\hline No & 10 & 39.5 & $5.0-68.5$ & & \\
\hline Tumor size $(\mathrm{cm})$ & & & & 3.901 & 0.048 \\
\hline$\geq 5$ & 13 & 26.0 & $8.5-65.0$ & & \\
\hline$<5$ & 9 & 51.0 & $6.0-140.0$ & & \\
\hline Extent of resection & & & & 0.036 & 0.850 \\
\hline STG & 13 & 18.0 & $5.5-112.0$ & & \\
\hline TG & 9 & 37.0 & $9.5-99.0$ & & \\
\hline Curability & & & & 2.720 & 0.099 \\
\hline Yes & 14 & 44.0 & $12.0-86.0$ & & \\
\hline No & 8 & 8.0 & $4.5-101.0$ & & \\
\hline Lymphatic invasion & & & & 1.959 & 0.162 \\
\hline Yes & 17 & 18.0 & $7.0-61.5$ & & \\
\hline No & 5 & 46.0 & $3.0-156.5$ & & \\
\hline TNM stage ${ }^{b)}$ & & & & 10.135 & 0.038 \\
\hline II & 5 & 67.0 & $23.0-200.5$ & & \\
\hline III & 13 & 18.0 & $7.0-64.5$ & & \\
\hline IV & 4 & 6.0 & $5.0-12.5$ & & \\
\hline Histologic grade & & & & NA & NA \\
\hline $\mathrm{G} 2$ & 3 & 39.5 & NA & & \\
\hline G3 & 19 & 26.5 & $10.0-70.5$ & & \\
\hline Adjuvant therapy & & & & 2.259 & 0.133 \\
\hline Yes & 14 & 67.0 & $2.5-45.0$ & & \\
\hline No & 8 & 8.0 & $2.5-45.0$ & & \\
\hline
\end{tabular}

IQR, interquartile range; STG, subtotal gastrectomy; TG, total gastrectomy; TNM, tumor-node-metastasis; NA, not applicable.

a) Log-rank test. ${ }^{b}$ Tumor stage was defined according to European Neuroendocrine Tumor Society TNM staging system.

neuroendocrine tumors (GEP-NETs) and reported that no significant association between any of these symptoms and metastasis. In our study, no patient had a functional neoplasm. However, clinical symptoms, such as abdominal pain and melena, were associated with poor survival time in patients with GNETs.

According to the ENETS guidelines, GNETs should be treated according to their classification. The guidelines recommended that small, benign type 1 and 2 tumors be monitored or treated with minimal endoscopic or laparoscopic surgery. Type 3 tumors require radical gastrectomy. Kim et al. [4] reported that tumor recurrence in patients with grade $1 / 2$ tumors occurred most frequently in the remnant stomach, whereas that in patients with grade 3 or mixed-type tumors typically occurred at distant sites. In our study, patients with $<1 \mathrm{~cm}$ grade 1 or 2 tumors underwent endoscopic resection; no tumor recurrence in the remnant stomach was detected. Patients with $\geq 1 \mathrm{~cm}$ grade 2 tumors or grade 3 tumors underwent radical gastrectomy. The tumor recurred in the remnant stomach in one patient and at a distant site (such as the liver, distant lymph node, peritoneum, or brain) in six patients.

The WHO has suggested a size limit $(<1 \mathrm{~cm})$ for T1 tumors with benign behavior. Schott et al. [9] reported that $>80 \%$ of $<2$ $\mathrm{cm}$ tumors are benign, and that nonfunctional NETs are usually $>2 \mathrm{~cm}$ and malignant. Tang et al. [8] reported that tumor type and size are correlated significantly with metastasis. Moreover, their 

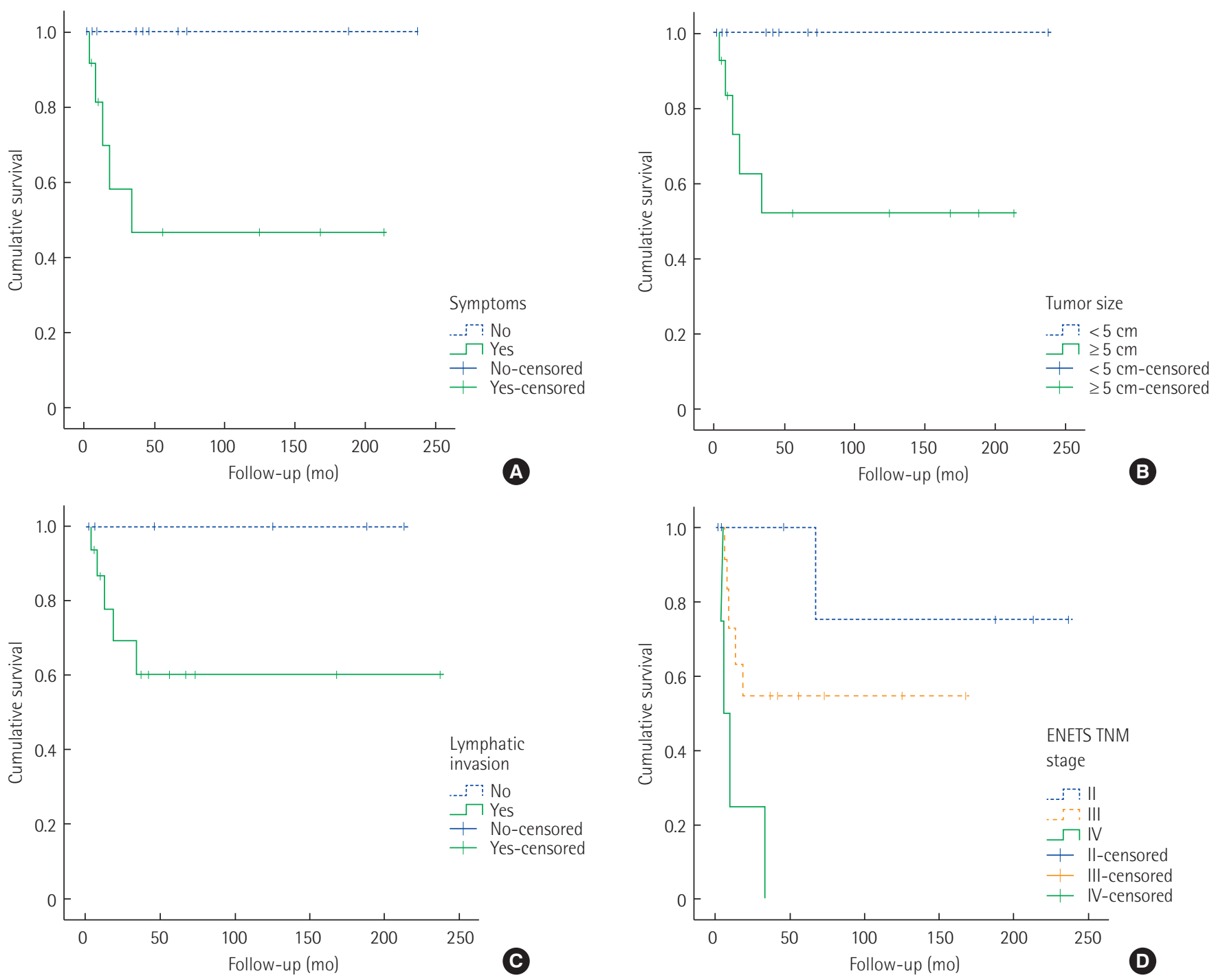

Fig. 2. Overall survival curves of gastric neuroendocrine tumors patients with surgical resection according to prognostic factors. (A) Symptoms, (B) tumor size, (C) lymphatic invasion, and (D) European Neuroendocrine Tumor Society (ENETS) tumor-node-metastasis (TNM) stage.

findings suggested that ulcerative types are more likely to metastasize than non-ulcerative types. Ozaslan et al. [10] reported that the Ki-67 value increases with increasing tumor size and disease stage. In this study, tumor size was significantly associated with survival, which is in agreement with an earlier report that a tumor size $\geq 2$ $\mathrm{cm}$ is a risk factor for metastasis.

Ki-67, a marker of cell proliferation, is present during all active phases of the cell cycle, such as $\mathrm{G}_{1}, \mathrm{~S}, \mathrm{G}_{2}$, and mitosis, but is absent in $\mathrm{G}_{0}[11,12]$. A high Ki-67 proliferation index indicates abnormal proliferation and tumor aggressiveness. Ozaslan et al. [10] reported that the decrease in survival rate with increasing tumor grade was more prominent than the decrease in survival rate with increasing tumor stage. They also suggested that the Ki-67 value is superior to tumor stage in terms of predicting the prognosis of patients with
GEP-NET. Nadler et al. [13] suggest that Ki-67 is a proliferative marker for NETs that is highly reproducible when used to grade tumors according to the ENETS and WHO staging systems. The study by Salama et al. [14] also supports this finding. Unfortunately, due to small sample size, in our study, histologic grade is not associated with survival in patients with surgical resection.

Synaptophysin (Syn), chromogranin A (CgA), CD56, and neuron-specific enolase are biomarkers of neuroendocrine differentiation that used for diagnosing neuroendocrine carcinoma. Several studies have assessed the associations of such biomarkers with prognosis in GNET patients [15-17]. Tang et al. [8] did not find a significant correlation between metastasis of GEP-NETs and biomarker expression by immunohistochemistry in 184 patients. However, Li et al. [18] reported that CD56 and CgA are predictive 
of the prognosis of patients with locoregional gastrin-independent GNETs. Wang et al. [19] analyzed patients with gastrointestinal NETs, and found that the 1- and 2-year survival rates were higher in CgA-positive than CgA-negative patients. In this study, biomarkers are not associated with patients' outcome (data not shown). Further studies are required to validate the utility of these biomarkers as independent prognostic factors.

The overall survival rate decreased with increasing disease stage in this study. Ozaslan et al. [10] reported that tumor grade influences survival, but did not detect an effect of disease stage. However, Scarpa et al. [20] reported that survival rate decreased with increasing disease stage. Pape et al. [21] reported that the newly proposed TNM classification system improved the assessment of survival in patients with GEP NETs. The relative risk of death increased 4 -fold and 30-fold for grade 2 and 3 NETs, respectively, compared with grade 1 NETs. In contrast, the relative risk of death for stage III and IV NETs was increased 3-fold and 9-fold, respectively, compared with that of stage II NETs.

Our study has some limitations. This is a retrospective study. We classified our patients according to WHO classification and ENETS staging system, which is a histological classification based on morphological criteria. The histological classification alone is not sufficient to predict clinical evolution. GNETs are very rare, so the statistical power of our analysis was limited by the relatively small number of patients. Finally, in our cohort, $40.73 \%$ of patients with grade 1 or 2 lesions received endoscopic resection and 59.3\% of patients with grade 3 lesions received gastrectomy. This difference between treatment methods could affect the sites of recurrence and lymph node metastasis.

In conclusion, clinical symptoms, tumor size, and TNM stage are associated with survival of patients with GNETs. Overall survival rate differs according to the stage of GNETs, which may thus be useful for prediction of prognosis.

\section{CONFLICT OF INTEREST}

No potential conflict of interest relevant to this article was reported.

\section{REFERENCES}

1. Chen WF, Zhou PH, Li QL, Xu MD, Yao LQ. Clinical impact of endoscopic submucosal dissection for gastric neuroendocrine tumors: a retrospective study from mainland China. ScientificWorldJournal 2012;2012:869769.

2. Dolcetta-Capuzzo A, Villa V, Albarello L, Franchi GM, Gemma M, Scavini M, et al. Gastroenteric neuroendocrine neoplasms classification: comparison of prognostic models. Cancer 2013;119:36-44.
3. Endo S, Dousei T, Yoshikawa Y, Hatanaka N, Taniyama K, Yamauchi A, et al. Gastric neuroendocrine tumors in our institutions according to the WHO 2010 classification. Int Surg 2012;97:335-9.

4. Kim BS, Park YS, Yook JH, Oh ST, Kim BS. Differing clinical courses and prognoses in patients with gastric neuroendocrine tumors based on the 2010-WHO classification scheme. Medicine (Baltimore) 2015;94:e1748.

5. Plockinger U, Rindi G, Arnold R, Eriksson B, Krenning EP, de Herder WW, et al. Guidelines for the diagnosis and treatment of neuroendocrine gastrointestinal tumours: a consensus statement on behalf of the European Neuroendocrine Tumour Society (ENETS). Neuroendocrinology 2004;80:394-424.

6. Eriksson B, Kloppel G, Krenning E, Ahlman H, Plockinger U, Wiedenmann $B$, et al. Consensus guidelines for the management of patients with digestive neuroendocrine tumors: well-differentiated jejunal-ileal tumor/carcinoma. Neuroendocrinology 2008;87:8-19.

7. Kuiper P, Verspaget HW, Overbeek LI, Biemond I, Lamers CB. An overview of the current diagnosis and recent developments in neuroendocrine tumours of the gastroenteropancreatic tract: the diagnostic approach. Neth J Med 2011;69:14-20.

8. Tang C, Gong L, Zou W, Zhang J, Zhou Y, Wu X, et al. Multivariate analysis of metastasis-related risk factors for patients with gastroenteropancreatic neuroendocrine tumors based on clinicopathological and endoscopic features. Oncol Rep 2016;36:3343-52.

9. Schott M, Kloppel G, Raffel A, Saleh A, Knoefel WT, Scherbaum WA. Neuroendocrine neoplasms of the gastrointestinal tract. Dtsch Arztebl Int 2011;108:305-12.

10. Ozaslan E, Demir S, Karaca H, Guven K. Evaluation of the concordance between the stage of the disease and Ki-67 proliferation index in gastroenteropancreatic neuroendocrine tumors. Eur J Gastroenterol Hepatol 2016;28:836-41.

11. Gerdes J, Lemke H, Baisch H, Wacker HH, Schwab U, Stein H. Cell cycle analysis of a cell proliferation-associated human nuclear antigen defined by the monoclonal antibody Ki-67. J Immunol 1984; 133:1710-5

12. Scholzen T, Gerdes J. The Ki-67 protein: from the known and the unknown. J Cell Physiol 2000;182:311-22.

13. Nadler A, Cukier M, Rowsell C, Kamali S, Feinberg Y, Singh S, et al. Ki-67 is a reliable pathological grading marker for neuroendocrine tumors. Virchows Arch 2013;462:501-5.

14. Salama A, Badawy O, Mokhtar N. Ki-67 is a powerful tool for grading neuroendocrine tumors among Egyptian patients: a 10year experience. J Cancer Res Clin Oncol 2014;140:653-61.

15. Belli SH, Oneto A, Aranda C, O'Connor JM, Domenichini E, Roca $\mathrm{E}$, et al. Chromogranin A as a biochemical marker for the management of neuroendocrine tumors: a multicenter study developed in Argentina. Acta Gastroenterol Latinoam 2009;39:184-9. 
16. Chou WC, Hung YS, Hsu JT, Chen JS, Lu CH, Hwang TL, et al. Chromogranin A is a reliable biomarker for gastroenteropancreatic neuroendocrine tumors in an Asian population of patients. Neuroendocrinology 2012;95:344-50.

17. Farinola MA, Weir EG, Ali SZ. CD56 expression of neuroendocrine neoplasms on immunophenotyping by flow cytometry: a novel diagnostic approach to fine-needle aspiration biopsy. Cancer 2003;99:240-6.

18. Li Y, Bi X, Zhao J, Huang Z, Zhou J, Li Z, et al. CEA level, radical surgery, CD56 and CgA expression are prognostic factors for patients with locoregional gastrin-independent GNET. Medicine (Baltimore) 2016;95:e3567.
19. Wang YH, Yang QC, Lin Y, Xue L, Chen MH, Chen J. Chromogranin $\mathrm{A}$ as a marker for diagnosis, treatment, and survival in patients with gastroenteropancreatic neuroendocrine neoplasm. Medicine (Baltimore) 2014;93:e247.

20. Scarpa A, Mantovani W, Capelli P, Beghelli S, Boninsegna L, Bettini R, et al. Pancreatic endocrine tumors: improved TNM staging and histopathological grading permit a clinically efficient prognostic stratification of patients. Mod Pathol 2010;23:824-33.

21. Pape UF, Jann H, Muller-Nordhorn J, Bockelbrink A, Berndt U, Willich SN, et al. Prognostic relevance of a novel TNM classification system for upper gastroenteropancreatic neuroendocrine tumors. Cancer 2008;113:256-65. 